\title{
Psycological and Physiological Responses to Stress: A Review Based on Results from PET and MRI Studies
}

\author{
Célia Martins Cortez*, Frederico Alan de Oliveira Cruz and Dilson Silva \\ Departamento de Ciências Fisiológicas; Instituto de Biologia Roberto Alcantara Gomes; Universidade do Estado \\ do Rio de Janeiro; Av. Professor Manoel de Abreu, 444; 20550170; ccortez@uerj.br; Rio de Janeiro - RJ - Brasil
}

\begin{abstract}
A new application for the nuclear imaging techniques is the study of organic responses to stress. Neuroimaging techniques allow the assessment of brain activation changes in association with the metabolic responses to stress. In this paper, a review of general effects of the stress on organic activity is made, emphasizing important advances introduced by studies using PET and FMRI. The importance of the hypothalamus-pituitary-adrenal axis to onset the adequate psychical and organic responses to sustain the homeostasis during the stress is discussed, as well as the possibility of traumatic stressing experiences have negative effects on the brain.
\end{abstract}

Key words: Stress, Nuclear imaging, physiological responses

\section{INTRODUCTION}

Nuclear imaging is efficient method to exploit the targeting of expressed cell-surface molecules and intracellular processes of several diseases and can to promote the development of innovative therapeutic interventions. Functional imaging with positron emission tomography (PET) and functional magnetic resonance imaging (fRMI) are nuclear imaging modalities that give information on tecidual metabolism and functioning, while computed tomography and magnetic resonance imaging (MRI) give anatomical information. PET is a technique which produces a three-dimensional image or map of functional processes in the body. The system detects pairs of gamma rays emitted indirectly by a positron-emitting radioisotope, which is introduced into the body on a metabolically active molecule. Images of metabolic activity in space are then reconstructed by computer analysis, often in modern scanners, alowing to visualize the radiotracer distribution in the body, and subtle changes in physiological performance in vivo (Ribeiro et al., 2007). PET is common imaging modality for clinical use in oncology and in many neurological diseases (Wiebe, 2007; Carter and Kotlyarov, 2007; Lomena and Soler, 2005).

A new application for the nuclear imaging techniques is the study of psychological and physiological responses to stress. Neuroimaging techniques allow the assessment of brain activation changes in association with the perception of and the metabolic response to stress. The biological stress is a reactive process, which reduces the negative effects caused by the stressor, constituting a state of resistance that has the final objective adapting the organism to the stressor effects (Cortez, 1991). Almost all change in our lives is a stressor stimulus. It is any kind of external situation that demands an organic and/or emotional equilibrium to deal with a new situation,

\footnotetext{
${ }^{*}$ Author for correspondence
} 
being this phase characterized by a larger energy requirement than that which the organism is accustomed to. Studies using fMRI has shown effectiveness of an acclimation process in minimizing the stressing experienced by the animal as assessed by alterations in physiological parameters including heart rate, respiratory rate, and serum GC levels (King et al., 2005). Despite the stress state can result from thousands of events, it is not an instantaneous and localized reaction, rather a reactive process which triggers a set of organic and behavioral responses related with pattern physiological changes, having as central pattern the hyperfunction of the adrenal gland (Cortez, 1991; Selye, 1946).

Stressor stimuli provoke firstly an immediate release of catecholamines (noradrenaline and adrenaline) from the adrenal medulla due to the strong sympathetic discharge, and then characteristic cardiovascular and metabolic effects are produced (Cortez, 1991). If the action of the stressor is not severe or of short duration, sympathetic and catecholamine effects can be suffice to restore or maintain the internal body equilibrium. Inversely, long-sustained exposure to stressor action provokes additional reactions, and the most significant of these is the increased release of glucocorticoids (GC) from adrenal cortex, establishing the stress state (Cortez and Silva 2007; Cortez et al., 2003; Selye, 1946). This hormone and its effects prepare the organism to satisfy the energetic demand and to increase the general defense, hence stress can be considered a syndromic state.

Selye (1946) defined Syndrome of General Adaptation (SGA) as the "sum of all the systemic non-specific reactions of the body resulting from a long-continued exposure to stress. It is distinct from specific adaptive reactions, such as the development of the musculature following prolonged physical exercise and the immunologic and allergic phenomena. Selye pointed to the implication of the sustained high production of GC from adrenal cortex in the stress.

Here, we present a review about psychological and physiological responses involved in stress state, emphasizing important advances introduced by studies using PET and MRI in this knowledge.

\section{Hypothalamus and Organic Responses to Stress}

The hypothalamus is the area of the central nervous system directly involved with the stress state, controlling numerous functions which are fundamental to life. The global functioning of the hypothalamus is fundamental for the genesis of the ideal internal conditions which the individual needs to adapt to the action of stressor. Through the autonomic nervous system and endocrine system, the hypothalamus starts a cascade of fundamental organic changes, such as glycemia regulation and control of cardiovascular, digestive and respiratory activities. Through its connections with reticular formation, the hypothalamus influences the regulation of sleep-wake cycle, and the attention grade, as well as in muscular tonus grade. In addition, hypothalamus aids in the preservation of organic harmony from the self mechanisms (corporal water and temperature regulation and feeding regulation) (Desvergne et al., 2006; van den Burg, 2005).

The regulatory capacity the hypothalamus has over the endocrine system is mainly due to its relation with the pituitary gland. Neurosecretory fibers produce the hypothalamic factors (or hormones) which regulate adenopituitary functions, influencing the production and release of its hormones. Corticotropin-releasing factor (CRF) is a neuropeptide released by hypothalamus that stimulates the liberation of adrenocorticotropin (ACTH) from the pituitary gland, and this hormone is the peripheral signaling to regulate the GC release by the adrenal cortex. Plasmatic GC ratio is regulated from a feedback mechanism on the HPA axis involving ACTH (Axelrold and Reisine, 1984). The interaction hypothalamuspituitary-adrenal, which involves the releasing of CRF, ACTH and GC, determine a functional axis called hypothalamic-pituitary-adrenal (HPA) axis. Thus, the stress provokes an organic response cascade. The circulating CRF and ACTH levels and organic GC-induced responses are influenced by several factors inherent to stress state, including the action of other hormones (Williamson, 2005). The endocrine stress-induced responses are very complex, and it is not easy to determine the scope of action of each hormone. Hormonal functions are complementary among them, and their responses modify with time. So, the stress is a dynamic process and the HPA axis plays a central role in the control of the response cascade.

\section{Stress Effects on the Cerebral Functions}

In human, HPA axis activity and cortisol release are consequences of central stress system activation, which displays the adequate organic 
responses to sustain its own requirements during the stress. There are evidences that the kind of cerebral control over neuroendocrine functions is dependent on the kind of activity which the cortex needs to develop. It was already been demonstrated that activities involving controllability of tasks influence both the sympathetic nervous system (including the release of catecholamine) and the release of cortisol, while mental effort has clear sympathetic responses, such as cardiovascular reactivity (Peters et al., 1998).

A study of regional brain metabolism using PET in humans showed the prefrontal cortex is activated in response to psychosocial stress; being prefrontal metabolic glucose patterns linked to the salivary cortisol concentration in response to subjective ratings on task stressfulness, controllability and mood states (Kern et al., 2008). In addition, a study using MRI showed significant differences in right but not left adult prefrontal volumes in young adult monkeys after conditions that are able to alter subsequent measures of HPA axis activity, emotional behavior and social propensities. The experience-dependent asymmetric variation was most clearly expressed in ventral medial cortex (Lyons et al., 2002).

Pruessner et al. (2008) proposed a model considering a reduction in limbic system activity is essential for the initiation of the stress response, based on results from PET and fMRI of human exposited to a psychosocial stressor. They observed a pronounced deactivation of limbic system components, including hippocampus, medio-orbitofrontal cortex, anterior cingulate cortex and hypothalamus, in subjects presenting a significant increase of plasmatic cortisol as response to stress. Experiments using PET, fMRI, electrical recording, and lesion studies have evidenced an important role anterior for the cingulated cortex in intelligent behavior, which depends on focused problem solving, error recognition, emotional self-control, and response to stressing conditions (Allman et al., 2001).

Spatial learning and memory, and neuroendocrine responses to psychological stress were examined in monkeys of the ages 5-17 years through cellular and molecular research combined with MRI (determination of regional volumes of gray and white matter). This period of lifespan development corresponds to the years 18-60 in humans. It was observed that older adults responded to stress with greater increases in plasma levels of ACTH and modest reductions in GC feedback sensitivity relative to young adults. Learning and memory did not differ with age during the initial cognitive test sessions, but older adults more often failed to inhibit the initial learned response after subsequent spatial reversals (Lyons et al., 2004).

Studies in animals have shown that intense stress can resulted in damage to the hippocampus with associated memory deficits. MRI showed reduction in volume of the hippocampus in combat veterans correlated with deficits in verbal memory on neuropsychological testing. These studies introduce the possibility that experiences in the form of traumatic stressors have long-term effects on the structure and function of the brain (Bremner, 1999), and can interfere in memory consolidation. It is known that the bilateral hippocampus ablation causes anterograde amnesia, i.e. amnesia for recent events, mainly for verbal information (Jonasson, 2004).

The conversion of initial labile memory representations into more permanent ones is called long-term memory consolidation, which is available for continued reactivation and recall over extended periods of time. The lconsolidation involves formation of new synapses and the reorganization of old ones. This is accompanied by a synthesis increase and structural remodeling of synaptic proteins, as well as of others membrane neuron components (Nelson et al., 2004; Cortez, 1991). The new synapse formation requires dendritic and axonal ramifications, involving also the protein metabolism increase for the restructuring and movement of the cytoskeleton (Cortez et al., 2007). From this move arises a growth cone, preliminary structure of ramification process and neuron cytoplasm extension, which precedes the synaptic connection (Komatsuzaki et al., 2005). Transmembrane potential has been pointed as being an important factor for the arising of the growth cone (Cortez et al., 2007), and several electrostatic theories have been developed to explain how physico-chemical properties can influence on the shape and deformation of membrane (Cruz et al., 2000; Soares and Cortez, 1999; Cortez and Bisch, 1993; 1995; 1996). According to Abbot and Regeher (2004), the synaptic plasticity and the range of operation timescales suggest that long-term changes in the transmission properties of synapses provide a physiological substrate for learning and memory, whereas short-term changes support a variety of computations. Indeed, synapses have a very active 
role in information processing, and several computational models of learning and memory, as well as motor-sensory processing, have been proposed in the last years, based on present knowledge about synaptic characteristic and neuronal processing (Cruz et al., 2007; Becker, 2005; Cruz and Cortez, 2005; Dalcin et al., 2005). Neuroimaging experiments have revealed that emotionally charged stimuli have a greater modulatory effect on sensorial cortex and some subcortical structures than on the neutral ones (Mourão-Miranda, 2003, Lane 1999). Actually, one person quickly gets used to low emotional significance stimuli; but this is not true for stimuli capable of raising intense emotion. However, it is important consider that depending on the intensity, the stimulation of brain GC-receptors may be beneficial or harmful to cognition. It was observed that GC can prevent or accelerate neurodegeneration in the adult rat hippocampus, suggesting a defensive GC role on hippocampus structures in the dependency of stress intensity (Patel et al., 2008).

Through MRI, da Rocha et al. (2006) studied the cases of Brazilian children presenting intelligence quotient scored less than 70. They found some signal of structural lesion in 50\% of MRI examinations, being a focal thinning at the junction of the body and splenium of the corpus callosum; ventricular asymmetry; periventricular leukomalacia; gliosis and arachnoid cysts the most frequent findings. Analysis of children history showed a large frequency of maternal stress in the prenatal phase.

\section{CONCLUSIONS}

Recent advances introduced by nuclear imaging provide new opportunities to elucidate neural mechanisms involved in stress state impossible to the assessing by other techniques. Studies using PET scan and fMRI have shown changes in cortical thickness, brain volume, blood flow and glucose metabolism in brain structures, associated to acutely elevated GC levels. Nuclear imaging techniques have also been efficient to examine links between specific psychological processes or disorders and brain activity, comparing effect of stress on healthy controls and pathological conditions, such as memory disorders, PTSD, substance abuse and others.
The intense cortical work and the great energy demand involved in psychic stress, due to numerous molecular syntheses (mainly of proteins and neurotransmitters), have been evidenced by several techniques. Such synthesis are related to the assembly of new neuronal circuits, the memory organization and learning. Despite the changes in the affective and ludic behavior, psychical or emotional stress of high amplitude causes functional alterations which may produce gradual biochemical depletions in the organism. These alterations may overcome the limit between stress and disease; breaking the equilibrium between the stressing forces (disequilibrium forces) and stress forces (resistance forces), causing negative effects on brain functions, such as damage in memory and learning process, weakening of cognitive functions and important behavior alterations.

\section{RESUMO}

Uma nova aplicação para as técnicas de imagem nuclear é o estudo de respostas orgânicas ao estresse. Técnicas de neuroimagem permitem observar as mudanças da ativação cerebral associadas às respostas metabólicas ao estresse. Neste artigo, uma revisão dos efeitos do estresse sobre a atividade orgânica é feita, enfatizando importantes avanços introduzidos por estudos realizados com PET e fMRI. A importância do eixo hipotálamo-hipófise-adrenal para o disparo das respostas orgânicas e psíquicas para a manutenção da homeostasia durante o estresse é discutida, bem como a possibilidade de experiências estressantes traumáticas exercerem efeitos negativos sobre o cérebro.

\section{REFERENCES}

Abbott, L. F.; Regehr, W. G. (2004), Synaptic computation. Nature, 431,796-803.

Allman, J. M., Hakeem, A., Erwin, J. M., Nimchinsky, E., Hof, P. (2001), The anterior cingulate cortex. Ann NY Acad. Sci., 935, 107-117.

Axelrold, J.; Reisine, T. D. (1984), Stress hormones: their interaction and regulation. Science, 224, 452459.

Becker, S. A. (2005), Computational principle for hippocampal learning and neurogenesis. Hippocampus, 15, 722-738.

Bremner, J. D. (1999), Does stress damage the brain? Biol Psychiatry, 45, 797-805. 
Carter, K. R.; Kotlyarov, E. (2007), Common causes of false positive $\mathrm{F}^{18}$ FDG PET/CT scans in oncology. Braz Arch Biol Technol., 50, 29-35.

Cortez, C. (1991), Stress and Its Physiological Inferences. Folha Médica, 103, 175-181.

Cortez, C.; Bisch, P. M. (1993), The Effect of Ionic Strenght and Outer Surface Charge on the Electric Potential Profile. Bioelectrochem Bioenerg., 32, 305315.

Cortez, C.; Bisch, P. M. (1995), Effect of Ionic Strenght and Outer Surface Charge on the Mechanical Stability of Erythrocyte Membrane. J Theor Biol. 176, 325-339.

Cortez, C.; Bisch, P. M. (1996), Inner Surface Charge and Membrane Mechanical Stability. A Theoretical Study applied to Red Blood Cell. Braz J Physics, 26, 604-610.

Cortez, C.; Costa, W. S; Babinski, M. A.; Chagas, M. A. (2003), Morphometrical and Stereological Analysis of the Superior Cervical Glanglion of Rattus norvegicus submitted to Chronic treatment with Cortisol. Intern J Morph., 21, 211-226.

Cortez, C. M.; Cruz, F. A. O.; Silva, D.; Costa, L. F. (2007), Influence of fixed electric charges on potential profile across the squid axon membrane. Physica B - Cond Matter, 403, 644-652.

Cortez, C. M.; Silva, D. (2007), Implicações do Estresse sobre à Saúde e Doença Mental. Arq Catarinenses Med., 36, 96-108.

Cruz, F. A. O.; Vilhena, F. S. D. S; Cortez, C. M. (2000). Solution of Non-linear Poisson-Boltzmann Equation for Eryithrocyte Membrane. Braz $J$ Physics., 30, 403-409.

da Rocha, A. F.; da Costa Leite, C.; Rocha, F. T.; Massad, E. (2006), Mental retadation: a MRI study of 146. Braz Children Arq Neuropsiquiat.; 64, 186-192.

Dalcin, B.; Cruz, F. A. O.; Cortez, C. M.; Passos, E. L. (2005), Computer Modeling of a Spinal Reflex Circuit. Braz J Physics.; 35, 987-994.

de Quervain, D. J.; Henke, K.; Aerni, A.; Treyer, V. (2003), Glucocorticoid-induced impairment of declarative memory retrieval is associated with reduced blood flow in the medial temporal lobe. Eur J Neurosci., 17, 1296-1302.

Desvergne, B.; Michalik, L.; Wahli, W. (2006), Transcriptional Regulation of Metabolism. Physiol Rev., 86, 465-514.

Jonasson, Z.; Ballantyne, J. K.; Baxter, M. G. (2004), Preserved anterograde and retrograde memory of rapidly acquired olfactory discrminations. Hippocampus, 14, 28-39.

Kern, S.; Oakes, T. R.; Stone, C. K.; McAuliff, E. M. (2008), Glucose metabolic changes in the prefrontal cortex are associated with HPA axis response to a psychosocial stressor. Psychoneuroendoc., 33, 517529.

King, J. A.; Garelick, T. S.; Brevard, M. E.; Chen, W. (2005), Procedure for minimizing stress for fMRI studies in conscious rats. J Neurosci Methods, 148, 154-160.

Komatsuzaki, Y.; Murakami, G.; Tsurugizawa, T.; Mukai, H.. (2005), Rapid spinogenesis of pyramidal neurons induced by activation of glucocorticoid receptors in adult male rat hippocampus. Biochem Biophys Res Commun., 335, 1002-1007.

Lane, R. D.; Chua, P. M. L.; Dolan, R. J. (1999), Common effects of emotional valence, arousal and attention on neural activation during processing of pictures. Neuropsychologia, 37, 989-997.

Lomena, F.; Soler, M. (2005), Clinical application of PET. Braz Arch Biol Technol., 48: 179-183.

Lyons, D. M.; Afarian, H.; Schatzberg, A. F.; SawyerGlover, A.; Moseley, M. E. (2002), Experiencedependent asymmetric variation in primate prefrontal morphology. Behav Brain Res., 136, 51-59.

Lyons, D. M.; Yang, C.; Eliez, S.; Reiss, A. L.; Schatzberg, A. F. (2004), Cognitive correlates of white matter growth and stress hormones in female squirrel monkey adults. J Neurosci., 24, 3655-3662.

Mayeda, A. R.; Simon J. R.; Hingtgen, J. N. (1989), Activity Wheel stress and Serotonergic hypersensivity in rat. Pharmacol Biochem Behav., 33, 349-353.

Mourão-Miranda, J.; Volchan, E.; Moll, J. (2003), Contributions of stimulus valence and arousal to visual activation during emotional perception. Neuroimage, 20, 1955-1963.

Papez, J. W. (1937), A proposed mechanisrn of emotion. Arch Neurol Psychiat., 38, 725-743.

Patel, P. D.; Katz, M.; Karssen, A. M.; Lyons, D. M. (2008), Stress-induced changes in corticosteroid receptor expression in primate hippocampus and prefrontal cortex. Psychoneuroendoc., 33, 360-367.

Pavlova, I. V.; Vanetsian, G. L. (2004), Evoked activity of the cat hypothalamus and amygdala under food motivation and in emotional stress. Ross. Fiziol $\mathrm{Zh} \mathrm{Im}$ I M Sechenova, 90, 1472-1484.

Peters, M. L.; Godaert, G. L.; Ballieux, R. E.; Van Vliet, M. (1998), Cardiovascular and endocrine responses to experimental stress. Psychoneuroendocr, 23, 1-17.

Pruessner, J. C.; Dedovic, K.; Khalili-Mahani, N.; Engert, V. (2008), Deactivation of the limbic system during acute psychosocial stress. Biol Psychiatry., 63, 234-240.

Ribeiro, C. G.; Moura, R.; Neves, R. F. (2007), Nuclear medicine imaging technique in the erectile dysfunction evaluation: a mini-review. Braz Arch Biol Technol., 50, 91-96.

Selye, H. (1946), The general adaptation syndrome and the diseases of adaptation. J Clin Endocrin Metab., 6, 117-196.

Soares, K. M.; Cortez, C. (1999), Linear Instability Analysis and Mechanical Interfacial Tension. J Theor Biol., 196, 169-179. 
Sze, P. Y.; Neckers, L. (1974), Requirements for adrenal glicocorticoid in the ethanol induced increase of tryptophan hydroxylase in mouse brain. Brain Res., 72, 375-378.

van den Burg, E. H.; Peeters, R. R.; Verhoye, M.; Meek, J. (2005), Brain responses to ambient temperature fluctuations in fish: reduction of blood volume. J Neurophysiol., 93, 2849-2855.

Weng, H. R.; Dougherty, P. M. (2002), Tuning of membrane properties regulates subliminal synapses in dorsal horn neurons of intact rats. Exp Neurol., 175, 209-215.
Wiebe, L. I. (2007), Applications of nucleosidebased molecular probes for the in vivo assessment of tumour biochemistry using PET. Braz Arch Biol Technol., 50, 445-459.

Williamson, M.; Bingham, B.; Viau, V. (2005), Central organization of androgen-sensitive pathways to the hypothalamic-pituitary-adrenal axis. Prog Neuropsychopharmacol Biol Psychiatry, 29, 12391248. 